
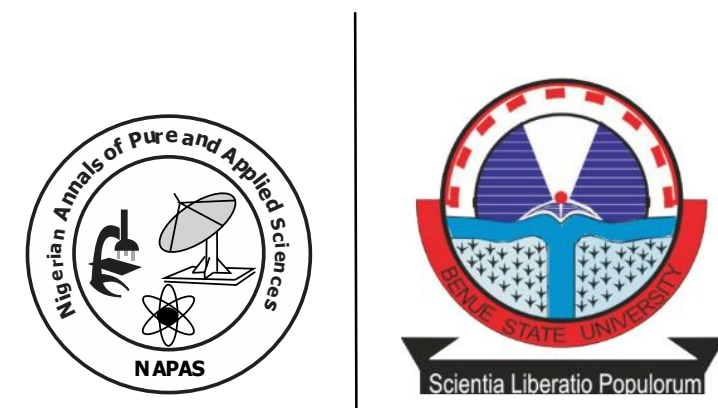

\title{
Aloe Vera (Aloe barbadensis Miller) Extract as a Natural Antimicrobial Agent in Hand-Washing Liquid Soap
}

\author{
Tyowua, A. T. ${ }^{1,2^{*}}$, Vitalis, T. B. ${ }^{1}$, Terhemen, M. M. ${ }^{2}$ and E. M. Mbaawuaga ${ }^{3}$ \\ ${ }_{1}^{1}$ Applied Colloid Science and Cosmeceutical Group, \\ Department of Chemistry, Benue State University, PMB 102119, \\ Makurdi, 970001, Nigeria \\ ${ }^{2}$ Hemary Pharmacy Laboratory, Akpehe, Makurdi, Nigeria \\ ${ }^{3}$ Department of Biological Science, Benue State University, \\ PMB 102119, Makurdi, 970001, Nigeria \\ *Corresponding author's e-mail/office: atyowua@bsum.edu.ng/+2349084232018
}

\begin{abstract}
Synthetic antimicrobial agents, like triclosan, used in many cosmetics are now associated with serious health problems, beginning with skin irritation to cancer. This calls for alternative antimicrobial agents. Many plant extracts have the potential to inhibit the growth of microorganisms and perhaps kill them and thus can serve as alternative antimicrobial agents in cosmetic formulations. To demonstrate this, a hand-washing liquid soap was prepared in the presence of varying concentrations of aloe vera extract and tested in-vitro against common skin microbes. First, a liquid soap paste was prepared by saponifying a vegetable oil blend containing olive oil ( 80.0 $\% \mathrm{w} / \mathrm{w})$, coconut oil $(14.3 \% \mathrm{w} / \mathrm{w})$ and castor oil $(5.7 \% \mathrm{w} / \mathrm{w})$ with aqueous $\mathrm{KOH}$ solution $(22.5 \% \mathrm{w} / \mathrm{w})$ at a relatively high temperature $\left(200{ }^{\circ} \mathrm{C}\right)$. Second, the soap paste was diluted with distilled water in the presence of varying concentrations ( 0 to $66.67 \% \mathrm{w} / \mathrm{w}$ ) of aloe vera extract to obtain hand-washing liquid soap samples, with the extract acting as an antimicrobial agent. Third, the liquid soap solutions were characterised in terms of foaming, wetting and cleansing abilities and the ability to inhibit the growth of Staphylococcus aureus, Pseudomonas aeruginosa and the fungus Aspergillus flavus. These were compared with those of a commercial (Astonish) hand-washing liquid soap sample containing triclosan $(0.1 \% \mathrm{w} / \mathrm{w})$ as an antimicrobial agent. The liquid soap solutions exhibited excellent foaming, wetting and cleansing abilities, similar to the commercial liquid soap solution. In addition, the liquid soap solutions gave an average zone of inhibition between $9.0 \pm 0.3 \mathrm{~mm}$ and $11.0 \pm 0.2 \mathrm{~mm}$ for $S$. aureus, $7.0 \pm 0.1 \mathrm{~mm}$ and $10.0 \pm 0.2 \mathrm{~mm}$ for $P$. aeruginosa and also inhibited the growth of the fungus $A$. flavus. These results compare favourably $(p=0.05)$ with the commercial liquid soap solution, which gave an average inhibition zone of $9.0 \pm 0.1 \mathrm{~mm}$ for both bacteria and also inhibited the growth of the fungus. This indicates that aloe vera extract can be used as an antimicrobial agent in the formulation of antimicrobial hand-washing liquid soap and other related products, rather than synthetic agents which are inherently harmful.
\end{abstract}

Keywords: microorganisms, antimicrobial agents, cosmetics, saponification, soap 


\section{Introduction}

Triclosan, triclocarban, phenols, halogens, trichlorocarbonalide, hydrogen peroxide and alcohols are commonly used as antimicrobial agents in cosmetic formulations like liquid hand-washing soaps, solid soaps, disinfectants, deodorants, toothpastes and liquid sanitisers (Fraise et al., 2004). For example, many commercial hand-washing liquid soaps contain triclosan as an antimicrobial agent (Scalia et al.,1994). Triclosan, 2,4,4'-trichloro2 '-hydroxydiphenylether, is a synthetic organic compound which is bacteriostatic against a wide range of Gram-positive and Gram-negative bacteria. Triclosan also has a strong fungistatic property even at low concentrations (Scalia et al.,1994). Unfortunately, like many other synthetic organic antimicrobial agents, studies have linked triclosan with serious health problems, beginning with skin irritation to hormone disruption (Hond et al., 2013). Triclosan is also implicated in the resistance of bacteria to antibacterial agents (Syed et al., 2014). It has been reported that triclosan is capable of accumulating in the fatty tissues of the body to become absorbed across the skin (Calafat et al., 2008). Triclosan also has the ability to alter hormone regulation, thereby reducing thyroid levels lower than required for normal brain development and metabolism (Hinther et al., 2011). In addition, triclosan is not easily degradable and therefore persists in the environment for longer periods and as such it is frequently detected in stream water (Calafat $e t$ al., 2008; Halden and Paul, 2005; Montagner et al., 2014). This necessitates the search for new, effective, less harmful and environmentally benign antimicrobial agents for cosmetic formulations.

Phytochemicals, chemicals obtained from plants, exhibit significant antimicrobial properties against a myriad of microorganisms including fungi (Harborne, 1984; Anyanwu and Okoye, 2017; Duke et al., 2002) and may serve as potential sources of antimicrobial agents in cosmetic formulations (Campa and Baron, 2018). Because they are of biological origin, phytochemicals are less harmful and do not persist in the environment (Devappa et al., 2010). Although the antimicrobial properties of phytochemicals, their toxicity and their fate in the environment are well studied (Anyanwu and
Okoye, 2017), their applications are limited and it is hoped that they can replace the harmful synthetic organic antimicrobial agents in cosmetic formulations. For instance, aloe vera (Aloe barbadensis miller) contains phenolic acids/polyphenols, phytosterols, fatty acids, indoles, alkanes, pyrimidines, alkaloids, organic acids, aldehydes, dicarboxylic acids, ketones, saponins and alcohols as phytochemicals (Amar et al., 2008; Cock 2008, 2011). Aloe vera extract is reported to inhibit the growth of skin pathogenic micro-organisms like Gram-positive Staphylococcus aureus, Gram-negative Pseudomonas aeruginosa and the fungus Aspergillus flavus (Cock, 2008).S.aureusis implicated in atopic dermatitis, skin and soft tissue infections (Lowy, 1998), P.aeruginosa is associated with green nail syndrome and toe web infections (Deretic, 2000) and A.flavus is implicated in chronic granulomatous sinusitis, keratitis, wound infections and osteomyelitis seen in traumatic patients (Hedayati et al., 2007). On this basis, it is thought that cosmetic formulations containing aloe vera extract can inhibit the growth of these microorganisms and prevent medical conditions associated with them. Therefore, this paper aims to show, for the first time, the inhibitory activity of a handwashing liquid soap formulation, containing aloe vera extract, on S. aureus, P.aeruginosa, and A.flavus. In the liquid soap, the aloe vera extract acts as a natural antimicrobial agent indicating that it can replace the harmful synthetic antibacterial agents commonly found in antibacterial soaps and other cosmetics.

\section{Materials and Methods \\ Materials \\ Water and vegetable oils}

Distilled water and three vegetable oil samples were used. The oils were pamace olive oil (100\% pure) from Sun Mark Limited, UK while both coconut oil (100\% pure) and castor oil ( $100 \%$ pure) were from KTC Limited, UK. The vegetable oils were used as received. Vegetable oils are acylglycerols in which fatty acids are esterified to one or more of the alcohol groups in glycerol (Cagliari et al., 2011). Triacylglycerols are formed when all the alcohol groups are esterified. The fatty acids esterified to glycerol may be identical (homotriacylglycerols) or different (heterotriacylglycerols), saturated 
(saturated triacylglycerols) or unsaturated (unsaturated triacylglycerols). In some cases, one or two of the alcohol groups in glycerol are not esterified, leading to the formation of monoacylglycerols and diacylglycerols, respectively (Kalemba and Dabrowska, 2015). Acylglycerols are predominant in the seeds and/or fruits of oleaginous plants like olive (Oleae uropaea), coconut (Cocos nucifera) and castor (Ricinus communis). Their function is to store energy necessary to support the growth of seeds during the early stages of germination
(Cagliari et al., 2011). This notwithstanding, they are extracted and used for different industrial applications including soap production, in a process known as saponification, using either sodium hydroxide or potassium hydroxide. Both saponifiable free fatty acids and triacylglycerols are converted into soap molecules, which are sodium or potassium salts of the corresponding fatty acids (Spitz, 2016), during saponification as shown in Figure

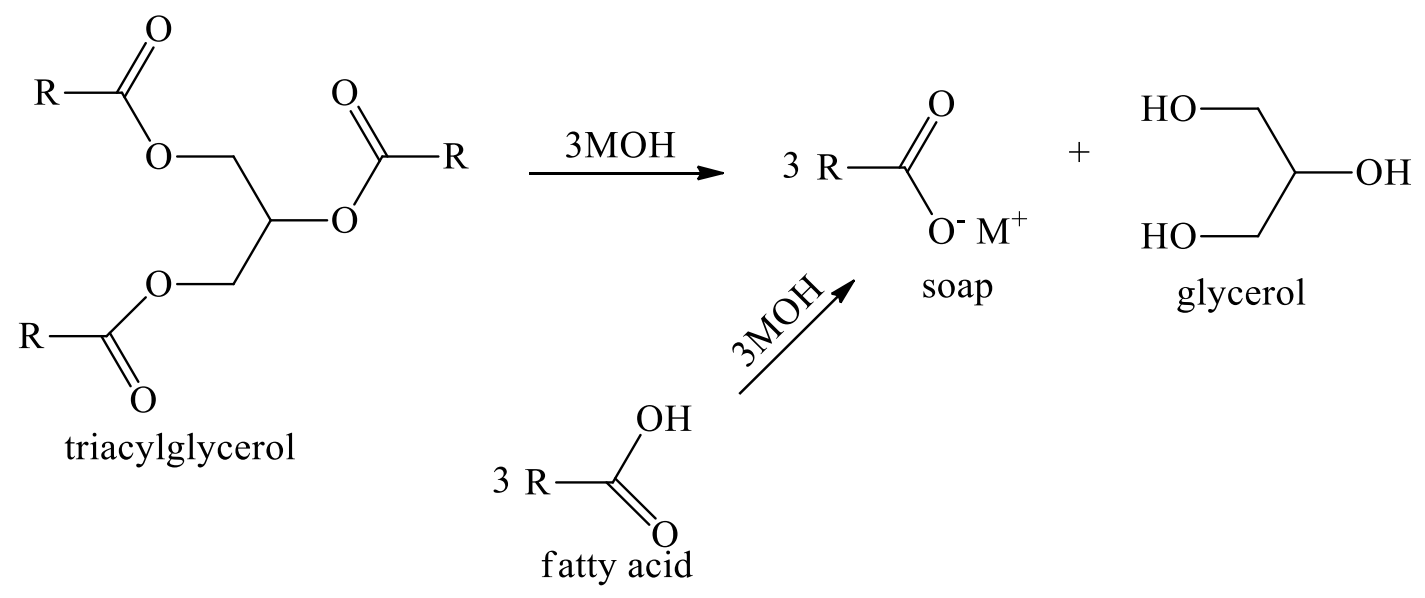

Figure 1. Illustration of saponification reaction for a hypothetic triacylglycerol and fatty acid, with one molecule of triacylglycerol yielding three soap molecules and a molecule of glycerol and a molecule of fatty acid yielding a soap molecule. The "R" and " $\mathrm{M}$ " represent an acyl group and sodium or potassium atom, respectively.

The fatty acids present in olive oil, coconut oil and castor oil are given in Table 1 along with their percentage composition. Olive oil is obtained by pressing olive fruit. The oil is rich in oleic acid (71\%) (Gunstone, 2002) and contains $98 \%$ saponifiableacylglycerols and free fatty acids (Gutfinger and Letan, 1974) and produces soaps with excellent moisturising property (Failor, 2000). Coconut oil is obtained by crushing and processing matured coconut kernels. Coconut oil is rich in lauric (45-52\%) and myristic (16-21\%) acids (Gunstone, 2002). The oil contains $99.5 \%$ saponifiableacylglycerols and free fatty acids (Gutfinger and Letan, 1974) and produces soaps that give plenty lather even in hard water (Failor, 2000). Castor oil is obtained by pressing the seeds of castor plant. Castor oil is rich in ricinoleic acid (89.5\%) (Gunstone, 2002) and contains $96.6 \%$ saponifiableacylglycerols and free fatty acids (Salimon et al., 2010). The oil produces colourless soaps with excellent emollient and moisturising properties (Failor,
2000). The oils were blended and used for the experiment so as to obtain a soap with synergistic properties, characteristic of soaps of the individual oil samples (Spitz, 2016). It must be understood that the oils were miscible due to the presence of similar intermolecular forces in them and that in the blend, the constituents of the individual oils did not react together.

\section{Chemical reagents and commercial soap}

Potassium hydroxide (85\% pure) from BDH Chemicals was used as the base or lye. Nutrient agar and potato dextrose agar, both from Sigma-Aldrich, were used for antibacterial and antifungal analysis tests, respectively. Finally, stearic acid, paraffin wax and $n$-hexane, used for various purposes were of analytical grade from Sigma-Aldrich. The Astonish handwashing liquid soap, from London Oil Refining Company Limited, UK, was used as a model commercial soap for the study. The soap contains a mixture of synthetic surfactants and 
triclosan, at one gram per kilogram (i.e. 0.1 $\% \mathrm{w} / \mathrm{w})$, as the active antimicrobial agent.

\section{Aloe vera}

Aloe vera leaves were obtained from the garden of Mr. Vitalis Terfa Bom in April 2018. Using the leaves, the plant was identified and authenticated by Mr. Joshua Waya (botanist) of the Biological Science Department, Benue State University, Makurdi. The leaves were washed with copious amount of distilled water, followed by aqueous hydrogen peroxide solution $(15 \% \mathrm{w} / \mathrm{w})$ before use.

\section{Microorganisms}

Three microorganisms (two bacteria and a fungus species) were used for antimicrobial analysis test. The analysis was carried out in the microbiology laboratory of the Benue State University, Makurdi. The test organisms were stock cultures of clinical isolates of Grampositive $S$. aureus and Gram-negative $P$. aeruginosa, maintained on nutrient agar slants at $4{ }^{\circ} \mathrm{C}$, and $A$. flavus, maintained on potatoes dextrose slant at the same temperature.

Table 1. Name, chemical structure and percentage composition of fatty acids found in olive, coconut and castor oils. Taken from (Gunstone, 2002).

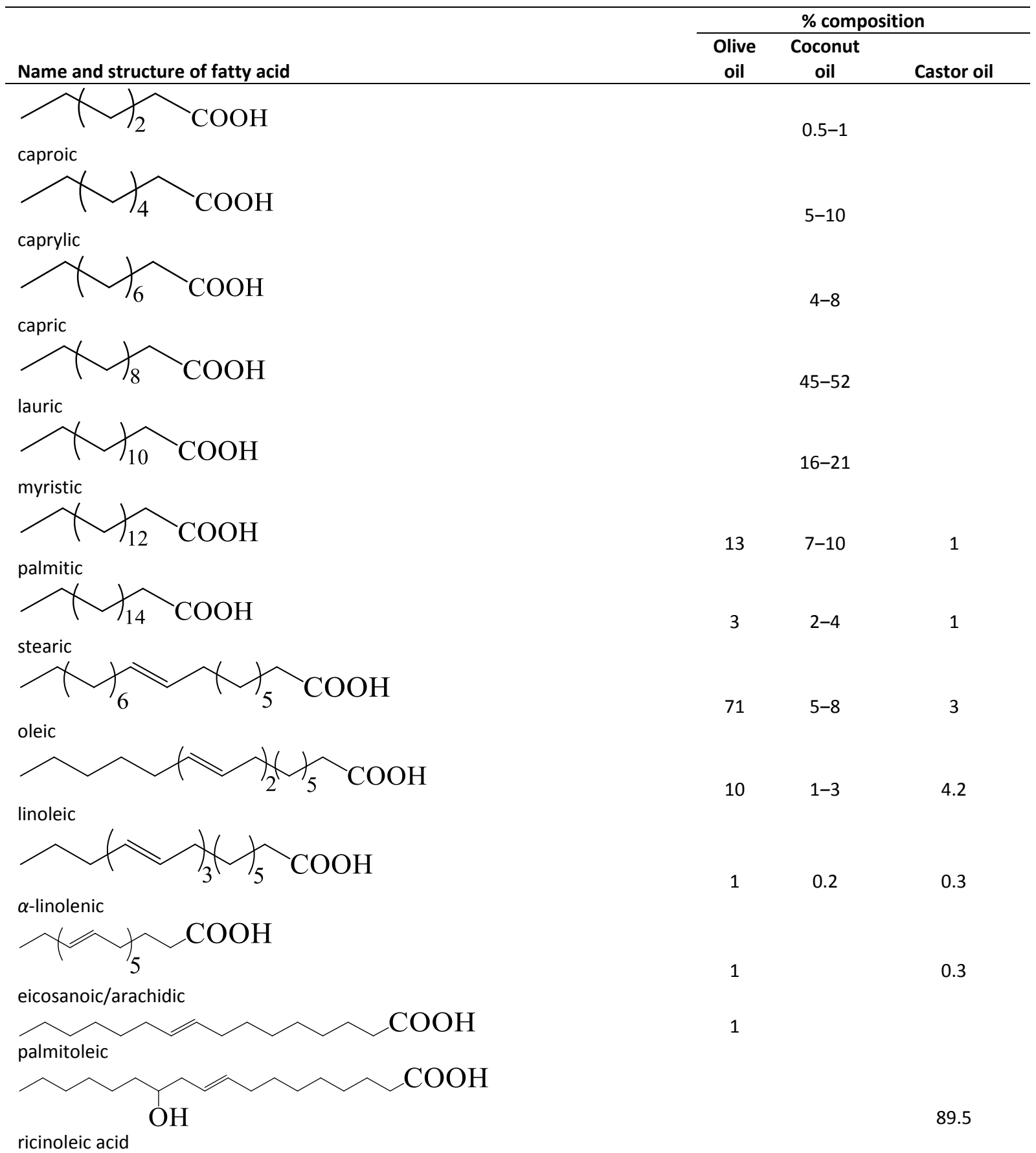


<smiles>CCCCCCCCC(O)C(O)CCCCCCCC(=O)O</smiles>

dihydroxystearic

\section{Methods}

\section{Determination of oil density}

The density of the oils was determined $\left(30 \pm 1{ }^{\circ} \mathrm{C}\right)$ using a density bottle. The density bottle was weighed while empty and when filled with an oil sample $\left(50 \mathrm{~cm}^{3}\right)$. The mass of the oil sample, corresponding to the volume, was obtained by taking the difference between the mass of the bottle when filled with the oil and when empty. The mass of the oil sample was divided by the corresponding volume to obtain the oil density, in line with Equation (1).

$$
\text { Oil density }=\frac{\text { mass of oil sample }(\mathrm{g})}{\text { corresponding volume of oil sample }\left(\mathrm{cm}^{3}\right)}
$$

For each oil sample, the average and the standard deviation of three separate density values were reported.

\section{Obtaining Aloe vera extract and incorporating it into liquid Soap}

Aloe vera leaves were cut into smaller pieces, using a knife, and then crushed (1000 g) using a hand-held electric stick blender (Food Processor, China) at a speed of 12000 revolutions per min to obtain a watery slurry $\left(500 \mathrm{~cm}^{3}\right)$. The slurry was filtered, first using a sieve of pores $0.01 \mathrm{~cm}^{2}$ and then using a linen of pores $30 \mu \mathrm{m}^{2}$. The filtrate was stored in an airtight glass bottle at a temperature of $10-15{ }^{\circ} \mathrm{C}$ in a refrigerator while the solid part of the plant left on the sieve and linen were discarded.

A soap paste was produced by saponifying an oil blend, composed of olive oil $(80.0 \% \mathrm{w} / \mathrm{w})$, coconut oil $(14.3 \% \mathrm{w} / \mathrm{w})$ and castor oil $(5.7 \% \mathrm{w} / \mathrm{w})$ with an aqueous solution of $\mathrm{KOH}(22.5 \% \mathrm{w} / \mathrm{w})$. The oil blend was heated to $160{ }^{\circ} \mathrm{C}$ on a hot plate in a stainless steel pot. After cooling to $95{ }^{\circ} \mathrm{C}$, the aqueous $\mathrm{KOH}$ solution was added. The mixture was heated to and maintained at $200{ }^{\circ} \mathrm{C}$ for one hour, with occasional stirring using a hand-held electric stick blender. As the mixture loses water, it became impossible to use the blender for stirring and a wooden stirrer was used until majority of the water molecules were evaporated, leaving the soap paste. The soap paste was allowed to cool to room temperature and then stored in plastic bags at $10-15{ }^{\circ} \mathrm{C}$ in a refrigerator. To obtain the hand-washing liquid soap, the soap paste (20 g) was dissolved in distilled water $(40 \mathrm{~g})$ at room temperature $\left(30 \pm 1{ }^{\circ} \mathrm{C}\right)$, containing varying amounts $(0.00$ to $66.67 \% \mathrm{w} / \mathrm{w})$ of aloe vera extract.

The yield of the soap paste was obtained from Equation (2).

Soap yield $=\frac{\text { actual yield of soap }(\mathrm{g})}{\text { theoreticd yield of soap }(\mathrm{g})} \times 100$

The "actual yield of soap" is the mass of soap paste obtained from the experiment while the "theoretical yield of soap" was calculated from the stoichiometry of the saponification reaction involving triacylglycerols (Figure 1). Homotriacylglycerols of the most abundant fatty acids in the vegetable oils were considered for the calculation. In line with this, trioleoylglycerol and tripalmitoylglycerol were used for olive oil, trilauroylglycerol and trimyristoylglycerol were used for coconut oil while triricinoleoylglycerol was used for castor oil. As reported by Salimon et. al., (2010), the percentage composition of the corresponding fatty acids (Table 1) was taken as a representative of the triacylglycerol composition. On this basis, olive oil was considered to contain $71 \%$ trioleoylglycerol and $13 \%$ tripalmitoylglycerol, coconut oil was considered to contain $45 \%$ trilauroylglycerol and $16 \%$ trimyristoylglycerol while castor oil was considered to contain $89.5 \%$ triricinoleoylglycerol. The calculation was done with a custom-made Microsoft Excel spread sheet and the sum of the theoretical yield of the separate triacylglycerols was taken as the theoretical yield of soap so that Equation (2) becomes

$$
\text { Soap yield }=\frac{\text { actual yield of soap }(\mathrm{g})}{\sum_{n=1}^{N} X_{n}(\mathrm{~g})} \times 100
$$


Where $X$ is the theoretical yield of soap when considering an $n$ triacylglycerol and $n=1,2,3, \ldots, N$.

\section{Characterisation of liquid soap}

The liquid soap samples were characterised in terms of $\mathrm{pH}$, foam production, wetting ability, cleansing ability and the ability to inhibit the growth of microorganisms (i.e. antibacterial and antifungal ability) and compared with the commercial hand-washing liquid soap.

\section{pH of soap solution}

For $\mathrm{pH}$, a soap sample (3 g) was dissolved in distilled water $(60 \mathrm{~g})$ and the $\mathrm{pH}$ of the resultant solution was measured using a Hanna Instruments HI9024 pH meter after calibration with suitable buffers.

\section{(b) Wetting ability}

For wetting ability, a ball of cotton wool $(1 \mathrm{~g})$ was placed on the surface of a soap solution containing $3 \mathrm{~g}$ of soap in $60 \mathrm{~cm}^{3}$ of distilled water at ambient conditions in a $100 \mathrm{~cm}^{3}$-beaker and the time taken for the cotton wool to sink was obtained.

\section{Foam production}

For foam production, a soap sample (1 g) was dissolved in distilled water $(20 \mathrm{~g})$ in a $50 \mathrm{~cm}^{3}$-measuring cylinder and agitated rapidly using an IKA T25 Ultra-turrax at a speed of 13000 revolutions per min for a period of $2 \mathrm{~min}$. The volume of foam produced immediately after agitation was measured.

\section{Cleansing ability}

For the cleansing ability, a linen cloth (4 $\mathrm{cm} \times 4 \mathrm{~cm}$ ), shown in Figure 2, was immersed $(30 \mathrm{~min})$ in a mixture containing $21.44 \% \mathrm{w} / \mathrm{w}$ of stearic acid, paraffin wax, olive oil and coconut oil all dissolved in $14.24 \% \mathrm{w} / \mathrm{w}$ of hexane. The photograph (Figure 2) of the linen and other photographs reported in this work were taken with a Canon PowerShot SX220 HS digital camera (Japan).

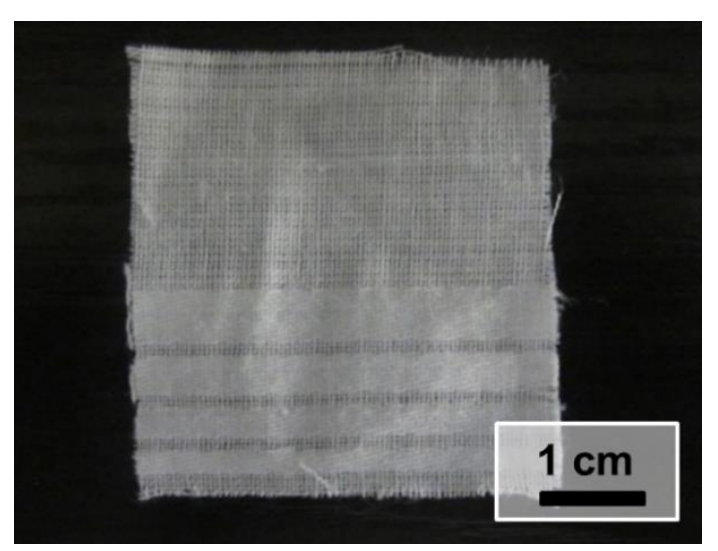

Figure 2.Photograph of a white linen cloth $(4 \mathrm{~cm} \times 4 \mathrm{~cm})$. The cloth was used to test the cleansing ability of the hand-washing liquid soap samples.

The linen was placed in a petri dish and dried in an oven (at $60{ }^{\circ} \mathrm{C}$ ) to a known constant mass and then immersed (30 $\mathrm{min}$ ) in an aqueous soap solution containing $4.76 \% \mathrm{w} / \mathrm{w}$ soap sample, followed by drying in air to a constant mass and then an oven $\left(60^{\circ} \mathrm{C}\right)$. The difference between the masses of the linen before and after immersing in the soap solution was expressed in percentage as a measure of the cleansing ability of the soap sample. This was compared with immersing the linen in only distilled water.

\section{(e) Antimicrobial analysis}

For the ability to inhibit the growth of micro-organisms, isolates of S.aureus, $P$. aeruginosa and A. flavus were subcultured onto freshly prepared nutrient agar plates and potatoes dextrose agar, respectively. Suspensions of $24 \mathrm{~h}$ growth of S.aureus and $P$. aeruginosa were made in sterile normal saline. The turbidity of the microorganism suspensions was adjusted to match that of 
a 0.5 McFarland standard, corresponding to approximately $1.5 \times 10^{8} \mathrm{CFU} / \mathrm{mL}$. Nutrient agar media, prepared in petri dishes, were inoculated (streaked) with the bacteria using the suspension with the aid of a sterile cotton swab. Sterile filter paper discs (diameter $6 \mathrm{~mm}$ ) were each impregnated with aqueous solution (20 $\mu \mathrm{L})$ of liquid soap sample $(50 \% \mathrm{w} / \mathrm{w})$ using an Eppendorf micropipette. The impregnated discs were placed on the streak agar plates, incubated $\left(37^{\circ} \mathrm{C}\right)$ for $24 \mathrm{~h}$ and the diameters of growth inhibition zones were measured using a digital Vanier calliper. Each test was done in triplicate and the results are expressed as mean values \pm standard deviation. The differences between the average growth inhibition zones of the commercial soap sample and the soap sample solutions were analysed using paired samples $t$-test at $95 \%$ confidence level. This was done with IBM SPSS Statistics programme version 20 (IBM Corp., Armonk, NY, USA) for Windows.

To test for antifungal activity, a soap sample $\left(2 \mathrm{~cm}^{3}\right)$ was thoroughly mixed with molten potatoes dextrose agar $\left(20 \mathrm{~cm}^{3}\right)$ in a petri dish and allowed to solidify and the test fungus was inoculated centrally in a well (diameter 4 $\mathrm{mm})$. For each case, the petri dish was incubated $\left(30{ }^{\circ} \mathrm{C}\right.$ ) for five days before investigating for fungus growth inhibition.

\section{Results and Discussion Oil density}

Density is a vital physical property of all substances and it is a measure of the mass occupied by a given volume of a substance. The density of coconut, olive and castor oils was obtained as $0.769 \pm 0.008,0.770 \pm 0.008$ and $0.959 \pm 0.008 \mathrm{~g} \mathrm{~cm}^{-3}$, respectively at $30{ }^{\circ} \mathrm{C}$, in increasing order of magnitude. This indicates that castor oil is denser than the rest of the oils while coconut oil is lighter than olive oil and castor oil. The density of these oils agree with values reported by (Akpan et al., 2006) while using the same method at the same temperature.

\section{Liquid soap containing Aloe veraextract}

The crushing and filtering of aloe vera leaves $(1000 \mathrm{~g})$ gave a watery slurry $\left(500 \mathrm{~cm}^{3}\right)$ extract. The saponification of the olive oilcoconut oil-castor oil blend (1000 g) with potassium hydroxide yielded ( $195 \mathrm{~g})$ dissolved in distilled water $(\sim 671 \mathrm{~g})$ gave $\sim 870 \mathrm{~g}$ soap paste. This can be compared with the theoretical yield of $\sim 883 \mathrm{~g}$, obtained by summing the theoretical yield of the individual oils, i.e. 730.64 $\mathrm{g}$ from olive oil, $97.30 \mathrm{~g}$ from coconut oil and $55.18 \mathrm{~g}$ from castor oil. Therefore, the percentage yield of soap paste, as obtained from Equation (3) is $\sim 98.53 \%$. This is good yield, despite neglecting low composition triacylglycerols, indicative that almost all the triacylglycerols have been converted to soap molecules. The dilution of the soap paste $(20 \mathrm{~g})$, Figure $3 \mathrm{a}$, with distilled water (40 g) containing varying concentrations $(0.00$ to $66.67 \% \mathrm{w} / \mathrm{w})$ of aloe vera extract gave hand-washing liquid soaps (Figure 3b) with aloe vera as a natural antimicrobial agent.

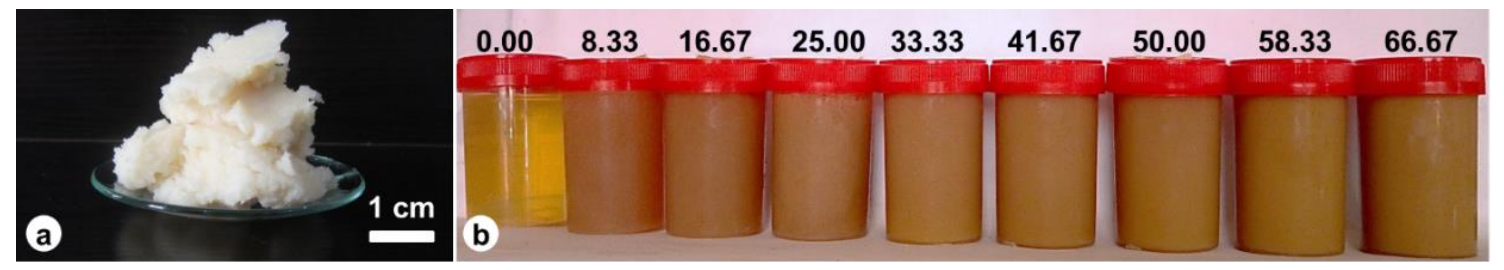

Figure 3. (a) Photograph of soap paste (100 g) on a Pyrex watch glass. The soap paste was stored ( $24 \mathrm{~h})$ in a refrigerator before placing on the watch glass. (b) Photograph of hand-washing liquid soap samples containing various concentrations $(\% \mathrm{w} / \mathrm{w})$ of aloe vera extract. The photograph was taken $24 \mathrm{~h}$ after preparation of the soap samples. 

The soap paste is white and gives a transparent liquid soap when diluted with distilled water alone (Figure 3). With aloe vera extract, it gives a brownish liquid soap and the colour deepens as the concentration of aloe extract increases probably due to some sort of reactions between the extract and the soap paste. The liquid soap samples remain stable and did not separate and deteriorate for more than a year.

\section{Characteristics of hand-washing liquid soap}

The characteristics of the hand-washing liquid soap samples would be discussed, in comparison with the commercial hand-washing liquid antimicrobial soap (Astonish), containing triclosan $(0.1 \% \mathrm{w} / \mathrm{w})$ as an antimicrobial agent. The discussion will be first in terms of $\mathrm{pH}$, second in terms of wetting ability, third in terms of foaming ability, fourth in terms of cleansing ability and lastly in terms of antimicrobial activity.

\section{pH of soap solution}

$\mathrm{pH}$ is a measure of the degree of hydrogen ion concentration in a solution. Solutions with $\mathrm{pH}$ below 7 are said to be acidic, those with $\mathrm{pH}$ above 7 are said to be basic while those with $\mathrm{pH}$ of 7 are said to be neutral. The hand-washing liquid soap samples are basic $(\mathrm{pH} \approx 10)$ irrespective of the aloe vera extract concentration even when diluted at a soap to water ratio of $1: 20$. This can be compared with the commercial handwashing liquid soap which is also basic with the same $\mathrm{pH}$ even when diluted to the same ratio. This is consistent with the $\mathrm{pH}$ of many soap-based cleansers, with values between 9 and 12, reported previously (Baranda et al., 2002; Gibson et al., 2002; Waranya and Pacharee,
2010). This is in contrast to the human skin $\mathrm{pH}$ which is acidic with values between 4 and 6. Although it is argued that the acidic $\mathrm{pH}$ is necessary for the defensive function of the skin against microorganisms (Ali and Yosipovitch, 2013), hand-washing soap solutions are often basic.

\section{Wetting ability}

The wetting ability of a soap solution is related to its ability to displace air from a material. At a soap to water ratio of 1:2, irrespective of the aloe vera concentration, it took $4 \mathrm{~s}$ for a cotton bud (60 g) to become completely wetted and sink in the soap sample solutions just like the commercial soap solution. In contrast, the cotton bud become completely wetted and sink in distilled water after $7 \mathrm{~s}$. This shows that the soap solutions and the commercial soap solution have relatively high wetting ability. Soap solutions with relatively high wetting ability generally have good cleansing ability (Chen et al., 2010) and thus the soap sample solutions and the commercial soap solution are expected to have good cleansing ability.

\section{(c) Foam production}

The agitation of the soap samples $(1 \mathrm{~g})$ in $100 \mathrm{~cm}^{3}$-measuring cylinders, containing water $(20 \mathrm{~g})$ and measuring the foam volume immediately after agitation, gave an insight into the foaming ability of the soap samples. Photographs of glass cylinders containing foams from the soap samples and the commercial one, immediately after agitation, are shown in Figure 4.

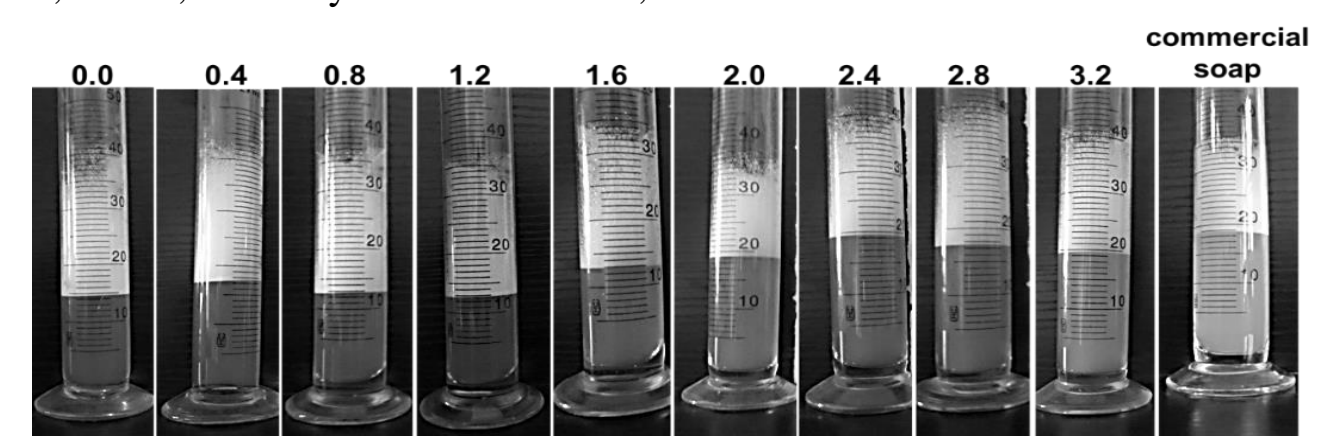

Figure 4. Photographs of glass cylinders containing foams of the soap sample solutions, and the commercial soap solution, at various concentrations (given, $\% \mathrm{w} / \mathrm{w}$ ) of aloe extract. The photographs were taken immediately after foam formation. 
The volume of foam obtained immediately after agitation is plotted in Figure 5 against the concentration of aloe extract in the soap sample solutions.

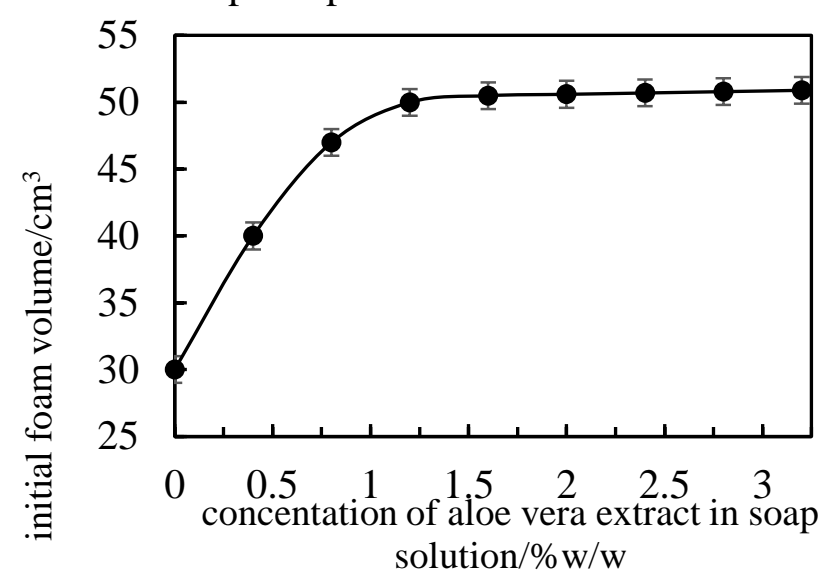

Figure 5. Initial foam volume versus concentration of aloe vera extract in soap sample solution.

The volume of foam obtained increases with increasing aloe vera extract concentration and reaches a constant value $\left(50 \mathrm{~cm}^{3}\right)$ at concentrations $\geq 1.2 \% \mathrm{w} / \mathrm{w}$. This can be compared with the volume $\left(30 \mathrm{~cm}^{3}\right)$ of foam obtained from the soap sample solution without aloe vera extract. Similarly, the commercial soap solution (of the same dilution) produced a maximum of $50 \mathrm{~cm}^{3}$ foam. This shows that at 1.2 $\% \mathrm{w} / \mathrm{w}$ extract and beyond, the soap sample solutions have the same foaming ability as the commercial soap. The increase in foam volume with aloe vera extract concentration is perhaps due to the presence of some natural foaming phytochemicals, e.g. saponins in the extract (Chen et al., 2010). Initially, the phytochemicals are in the monomeric state with the ability to stabilise more air bubbles as their concentration increases, leading to increasing foam volume. The phytochemicals transitioned to stable aggregates as their concentration increased beyond a critical value, losing their ability to stabilise air bubbles and the foam volume becomes independent of their concentration (Azira et al., 2008). This is the scenario with many foaming agents (Tyowua et al., 2012).

\section{(d) Cleansing ability}

The determination of the mass of oil mixture removed by the soap sample solutions, when a linen cloth was immersed in their solution for a period of $30 \mathrm{~min}$ served as a measure of their cleansing ability. Irrespective of the concentration of aloe vera extract, the soap sample solutions were able to remove $91 \% \mathrm{w} / \mathrm{w}$ of the oil mixture on the linen. The same amount of the mixture was removed by the commercial soap. This clearly indicates that the soap sample solutions and the commercial soap solution have the same cleansing ability. This is in contrast to water alone which was able to remove only $2 \% \mathrm{w} / \mathrm{w}$ of the mixture from the linen cloth and a crude saponin solution which is reported (Chen et al., 2010) to remove $53.8 \% \mathrm{w} / \mathrm{w}$ of a similar mixture.

\section{(e) Antimicrobial analysis}

The ability of the liquid soap samples to inhibit the growth of microorganisms was studied using two modelled bacteria ( $S$. aureus and $P$. aeruginosa) and a fungus species (A. flavus) and compared with that of the commercial liquid soap. The well diffusion method was used to gain insight into the antibacterial property of the soap samples, by measuring the diameters of zones of bacterial growth inhibition. The poisoned food method was used for the fungus and the extent of fungi growth on the plate was noted. A plot of the diameters of zones of bacterial growth inhibition against the concentration of aloe extract in the soap solution is shown in Figure 6 . 


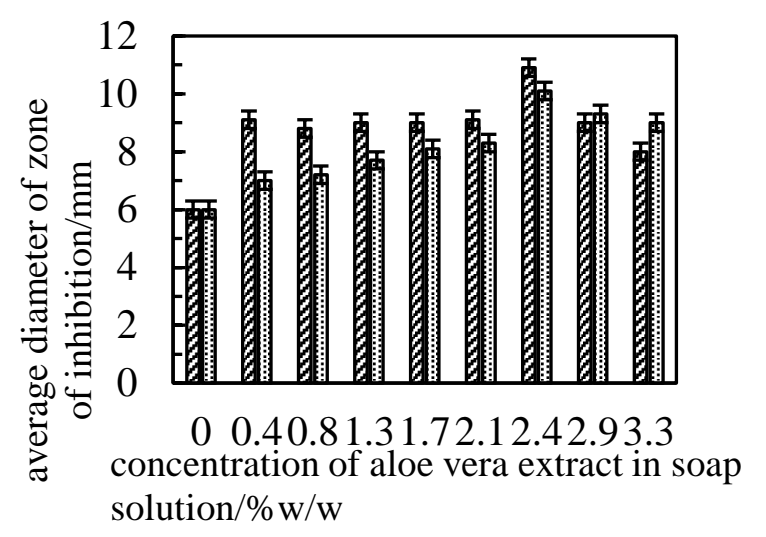

Figure 6. Plot of average diameter of zone of inhibition for S. aureus (שיC) and P. aeruginosa (囚) versus concentration of aloe vera extract in soap solution. The error bars are standard deviation of triplicate measurement.

The soap solution without aloe vera extract inhibited the growth of both bacteria up to an average of $6.0 \pm 0.1 \mathrm{~mm}$. This is probably due to the presence of unsaponified components of the oil blend (Thormar, 2011). As expected, the incorporation of the extract increased the zone of inhibition significantly $(p=0.05)$ to an average of between $9.0 \pm 0.3 \mathrm{~mm}$ and $11.0 \pm 0.2 \mathrm{~mm}$ for $S$. aureus and between $7.0 \pm 0.1 \mathrm{~mm}$ and $\quad 10.0 \pm 0.2 \mathrm{~mm}$ for $P$. aeruginosa. This can be compared with the aloe vera extract alone which gave an average inhibition zone of $9.0 \pm 0.2 \mathrm{~mm}$ for both bacteria, and $11 \mathrm{~mm}$ for $P$. aeruginosa and $15 \mathrm{~mm}$ for $S$. aureusas reported by Philip et al., (2012). Statistical analysis shows that there is no significant difference $(p=0.05)$ in the activity of the extract when incorporated in the liquid soap. These results compare favourably $(p=0.05)$ with the commercial soap solution, which gave an average inhibition zone of $9.0 \pm 0.1 \mathrm{~mm}$ for both bacteria.

By inoculating A. flavus in potatoes dextrose agar, containing the soap sample solutions followed by incubation, the effect of aloe vera extract (in the soap sample solution) on the fungus was investigated. Figure 7 contains photographs of petri dishes, containing A. flavus at various concentrations of aloe vera extract in the soap sample solution after incubation $\left(30^{\circ} \mathrm{C}\right)$ for five days.

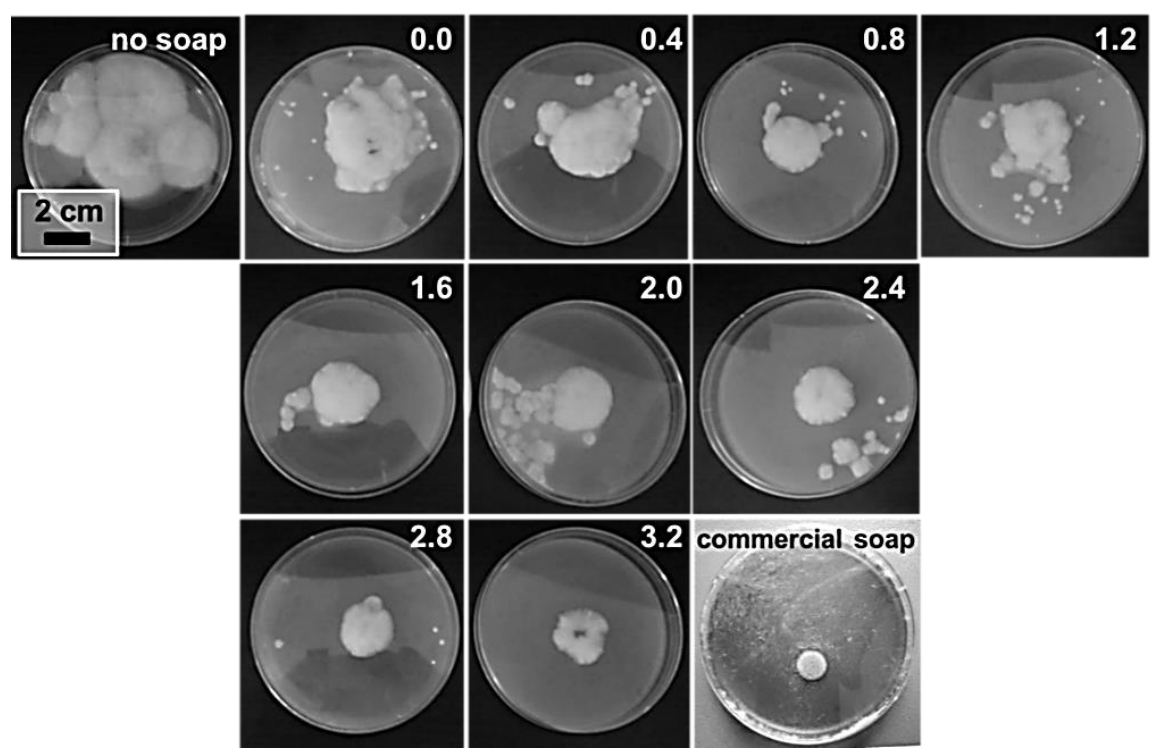

Figure 7. Photographs of petri dishes, containing A. flavusat various concentrations (\%w/w) of aloe vera extract in the soap sample solution, after incubation $\left(30^{\circ} \mathrm{C}\right)$ for five days. The petri dishes without the soap sample solutions and the commercial soap solution are also shown for comparison. 
As can be seen, the petri dish without a soap solution shows significant growth of $A$. flavus. The growth of $A$. flavus decreases slightly in the presence of the soap sample solution containing no aloe vera extract. The extent of the fungus growth decreased with increasing aloe vera extract concentration so that at concentrations between 2.8 and $3.2 \% \mathrm{w} / \mathrm{w}$, the fungus only grew in a small area. The growth of A. flavus between these concentrations is similar to that in the dish containing the commercial soap solution where triclosan $(0.1 \% \mathrm{w} / \mathrm{w})$ is the active ingredient.

\section{Conclusions}

A soap paste was obtained by saponifying an oil blend containing olive oil, coconut oil and castor oil with potassium hydroxide solution. The soap paste was diluted with distilled water containing aloe vera extract to obtain antimicrobial hand-washing liquid soap samples, with the aloe vera extract acting as a natural antimicrobial agent. The soap sample solutions produced plenty foam when agitated and has excellent cleansing ability. In addition, the soap sample solutions are able to inhibit the growth of certain skin microorganisms like Gram-positive $S$. aureus, Gram-negative $P$. aeruginosa and the fungus $A$. flavus. These properties compare closely ( $p=0.05$ ) with those of a typical commercial antimicrobial handwashing liquid soap, containing triclosan as an antimicrobial agent. This indicates that aloe vera extract can be used as a natural antimicrobial agent in the formulation of antimicrobial handwashing liquid soap and other related products in the cosmetic industry.

\section{Acknowledgements}

We are grateful to Mr. Joshua Waya for plant species authentication, Mrs. Aondo Terkaa Ogooluwa for antimicrobial analysis and $\mathrm{Mr}$. Criscent Eya for statistical analysis.

\section{References}

Akpan, U.G., Jimoh, A. and Mohammed, A.D. (2006). Extraction, characterisation and modificaton of castor seed oil. Leonardo J. Sci., 8: 43-52.

Ali, S.M. and Yosipovitch, G. (2013). Skin pH: from basic science to basic skin care. Acta. Derm. Venereol., 93: 261-267.
Amar, S., Vasani, R. and Saple, D.G. (2008). Aloe vera: a short review. Indian J. Dermatol., 53(4): 163-166.

Anyanwu, M.U. and Okoye, R.C. (2017). Antimicrobial activity of Nigerian medicinal plants. J. Intercult. Ethnopharmacol., 6(2): 240-259.

Azira, H., Tazerouti, A. and Canselier, J.P. (2008). Study of foaming properties and effect of the isomeric distribution of some anionic surfactants. J. Surfactants Deterg., 11(4): 279-286.

Baranda, L., Gonzalez-Amaro, R., Torres-Alvarez, B., Alvarez, C. and Ramirez, V. (2002). Correlation between $\mathrm{pH}$ and irritant effect of cleansers marketed for dry skin. Int. J. Dermatol., 41: 494-499.

Cagliari, A., Margis, R., dos Santos Maraschin, F., Turchetto-Zolet, A.C., Loss, G. and Margis-Pinheiro, M. (2011). Biosynthesis of triacylglycerols (TAG) in plants and algae. Int. J. Plant Bio., 2(e10): 40-52.

Calafat, A.M., Ye, X., Wong, L.-Y., Reidy, J.A. and Needham, L.L. (2008). Urinary concentrations of triclosan in the U.S. population: 2003-2004. Environ. Health Perspect., 116(3): 303-307.

Campa, M. and Baron, E. (2018). Anti-aging effects of select Botanicals: scientific evidence and current trends. Cosmetics, 5(3): 54.

Chen, Y.-F., Yang, C.-H., Chang, M.-S., Ciou, Y.P. and Huang, Y.-C. (2010). Foam properties and detergent abilities of the saponins from Camellia oleifera. Int. J. Mol. Sci., 11: 4417-4425.

Cock, I.E. (2008). Antimicrobial Activity of Aloe barbadensis Miller Leaf Gel Components. Internet Journal of Microbiology, 4(2).

Cock, I.E. (2011). Problems of reproducibility and efficacy of bioassays using crude extracts, with reference to aloe vera. Pharmacogn. Commun., 1(1): 52-62.

Deretic, V. (2000). Pseudomonas aeruginosa infections, in Persistent bacterial infections. J. Nataro,M. Blaser and S. CunninghamRundles (Eds). Washington DC, ASM Press:305-326.

Devappa, R.K., Makkar, P.S. and Becker, K. (2010). Biodegradation of Jatropha curcas phorbol esters in soil. J. Sci. Food Agric., 90(12): 2090-2097.

Duke, J.A., Bogenschutz-Godwin, M.J., duCellier, J. and Duke, K.P.-A. (2002). Handbook of 
medicinal herbs. Boca Raton, Florida, CRC Press.

Failor, C. (2000). Making natural liquid soaps. Hong Kong, Storey Publishing.

Fraise, A.P., Lambert, P.A. and Maillard, J.-Y., Eds. (2004). Russell, Hugo and Ayliffe's Principles and practice of disinfection, preservation and sterilisation. Oxford, Blackwell Publishing.

Gibson, L.L., Rose, J.B., Haas, C.N., Gerba, C.P. and Rusin, P.A. (2002). Quantitative assessment of risk reduction from hand washing with antibacterial soaps. J. Appl. Microbiol. Sympo. Suppl., 92: 136S-143S.

Gunstone, F.D., Ed. (2002). Vegetable oils in food technology: composition, properties and uses. US and Canada, Blackwell Publishing.

Gutfinger, T. and Letan, A. (1974). Studies of unsaponifiables in several vegetable oils. Lipids, 9(9): 658-663.

Halden, R.U. and Paul, D.H. (2005). Cooccurrence of triclocarban and triclosan in US water resources. Environ. Sci. Technol., 39(1): 1420-1426.

Harborne, J.B. (1984). Phytochemical methods: a guide to modern techniques of plant analysis. New York, Chapman and Hall.

Hedayati, M.T., Pasqualotto, A.C., Warn, P.A., Bowyer, P. and Denning, D.W. (2007). Aspergillus flavus: human pathogen, allergen and mycotoxin producer. Microbiology, 153: 1677-1692.

Hinther, A., Bromba, C.M., Wulff, J.E. and Helbing, C.C. (2011). Effects of triclocarban, triclosan, and methyl triclosan on thyroid hormone action and stress in frog and mammalian culture systems. Environ. Sci. Technol., 45(5395-5402): 5395.

Hond, E.D., Paulussen, M., Geens, T., Bruckers, L., Baeyens, W., David, F., Dumont, E., Loots, L., Morrens, B., de Bellevaux, B.N., Nelen, V., Schoeters, G., van Larebeke, N. and Covaci, A. (2013). Biomarkers of human exposure to personal care products: results from Flemish Environment and Health Study (FLEHS 2007-2011)). Sci. Total Environ., 463-464: 102-110.
Kalemba, D. and Dabrowska, M. (2015). Chemistry of lipids. Research Signpost, 37(2): 1-19.

Lowy, F.D. (1998). Staphylococcus aureus infections. N. Engl. J. Med., 339: 520-532.

Montagner, C.C., Jardim, W.F., Von der Ohe, P.C. and Umbuzeiro, G.A. (2014). Occurrence and potential risk of triclosan in freshwaters of Sao Paulo, Brazil-the need for regulatory actions. Environ. Sci. Pollut. Res, 21(3): 1850-1858.

Philip, J., John, S. and Iyer, P. (2012). Antimicrobial activity of Aloevera barbedensis, Daucus carota, Emblica officinalis, Honey and Punica granatum and formulation of a health drink and salad. Malaysian J. Microbiol., 8(3): 141-147.

Salimon, J., Noor, D.A.M., Nazrizawati, A.T., Mohd Firdaus, M.Y. and Noraishah, A. (2010). Fatty acid composition and physicochemical properties of Malaysian castor bean Ricinus communis L. seed oil. Sains Malaysiana, 39(5): 761-764.

Scalia, S., Guarneri, M. and Menegatti, E. (1994). Assay of triclosan in deodorant sticks and soaps by supercritical fluid extraction and HPLC. J. Soc. Cosmet. Chem., 45: 35-42.

Spitz, L., Ed. (2016). Soap manufacturing technology. San Diego, Academic Press.

Syed, A.K., Ghosh, S., Love, N.G. and Boles, B.R. (2014). Triclosan promotes Staphylococcus aureus nasal colonisation. mBio, 5(2): e01015-01013.

Thormar, H., Ed. (2011). Lipids and essential oils as antimicrobial agents. Chichester, Jonh Wiley and Sons Ltd.

Tyowua, A.T., Yiase, S.G. and Wuana, R.A. (2012). Manipulation of concentrationconductivity data of sodium dodecyl sulphate and sodium dodecylbenzene sulphonate in $\mathrm{KCl}$ solution in relation to micellisationparameters. Astonjournals, CSJ-79: 1-9.

Waranya, B. and Pacharee, I. (2010). The pH of commonly available soaps, liquid cleansers, detergents and alcohols gels. Dermatitis, 21(3): 154-156. 